$\Phi=-1$ 圆

\title{
Social Construction of Masculine Women Identity
}

\author{
Zikri Fachrul Nurhadi $^{1 * 1}$, Ummu Salamah ${ }^{2}$, Yully Destari ${ }^{3}$, Novie Susanti Suseno ${ }^{4}$ \\ ${ }^{1,3}$ Department of Communication Science, Universitas Garut, Indonesia \\ ${ }^{2}$ Department of Social Welfare, Universitas Pasundan, Indonesia \\ ${ }^{4}$ Department of Accounting, Universitas Garut, Indonesia \\ *Corresponding author E-mail: zikri_fn@uniga.ac.id
}

\begin{abstract}
The purpose of this study to discover and reveal the social construction of masculine woman identity in terms of externalization, objectivation, and internalization. This study used a qualitative approach, with a method or theory of social reality construction of constructivism paradigm. Data collection was done through in-depth interviews, participant observation, and literature. The study finding showed that the social construction of masculine woman identity in terms of externalization is influenced by internal and external factors. Internal factor is influenced by a family that makes informants show the social construction of masculine woman identity to the public. While external factor is influenced by association with male friend and technological advances (mass media) that have contributed to the formation of character, appearance style, and feeling to others. In general, social identity construction of masculine woman constructs her identity in a way showed that masculine woman does not always have a negative character. In this case, a masculine woman can survive and adapt to the family, campus and community environments. The research finding showed that appearance changes will only happen if there is a will from the masculine woman herself, and the comfort level of masculine appearance can not change the identity.
\end{abstract}

Keywords: constructivism; identity; masculine; social construction; women

\section{Introduction}

Appearance is one of main priority for every individual for showing their identity to the others especially hair, the female is identically someone who always shows her beauty in order to look more attractive and beautiful. Besides that, women are also polite, soft and any other characteristics but there are some women who have characteristics like a man and it happens in our society, by looking the appearances is like a man such as having a crew cut style, like smoking even has a tattoo in her body. Female masculine generally is only a women who wants to be sandable person, tough, and strong personality (1). In history, male and female are generally supposed that hair is something beautiful, attractive, power and young sign. Hair is the source of the important non-verbal message. Those factors contribute towards the whole attractive and the function as the basic of personality traits including age, profession, behavior, belief and values, but it does not mean that the female masculine should act like the common female to show their feminism.

Masculine women in this research are intended to the students of Faculty of Communication, and Faculty of Maths and Science at Garut University. There are some students who look more comfortable by having masculine style. They look masculine style because they supposed that it is much more simple and relax. No wonder they get the bully from the other students, that is why only a few students who dare to look like the masculine style in Garut University.

Based on the collecting the data, there are some students who look like masculine among others: 4 students from Communication Faculty, 3 students from Economic Faculty and 2 students from Science and Maths Faculty, whereas there is no masculine stu- dent's style from Social Politic Faculty, Education and Religion Faculty. In Garut University, female masculine constructs their identities towards the society, especially in the campus. Appearance is a non-verbal concept to show the personal identity in order to get communicative and interactive behaviors from the people. Masculin appearances are one of non-verbal communication, that is the process of communication in which the message is not delivered by using some words. The example of non-verbal communication is to use sign movement, gesture, expression, eyes contact, the objects using is such as costumes, hairstyle. The symbols and style of speaking are such as intonation, stressing, sound quality, emotion and the style of speaking. Appearances are one of non-verbal communication that is to cut whether it will start to talk with other people or not, no wonder this is influenced by the appearance itself. Sometimes, the conclusion of the intelligence, social status, and profession of someone are proven of how she acts for instance in the way of wearing the clothes (2).

Many things that cause women decides that she resembles a male due to the above factors the family itself. Moreover, when she is the only one daughter in the family, so she will try to duplicate her brother's appearances although the difference of gender, feminism, and masculine are still existing. This circumstance is caused by the development of era towards to the modernization and rapidly feminism movement and influence the mindset of the society, it will be appearing new phenomenon and those circumstances are started to be changed. Nowadays, we mostly find out the phenomenon such as female looks like a male or on the vise verse, the husband takes care at home and the wife gets a job on the outside so the limitless between male and female are absolutely vague. This circumstance will influence the media especially electronic (3). 
Tomboy is a female who has got characteristic like a male such as wearing a male cloth or playing a male's games. The terminology of Tomboy comes from England, according to Oxford English Dictionary, it relates to the 'connotation rudeness'. According to Judith Hallberstam, gender expert, declares that a female who has a characteristic like a male is often bullie; however, the traditional clothes like a skirt, blouse, and gown have already decreased and sport's man is started to be more popular for a female so the tolerant is absolutely increase and the pejorative characteristic is lack. In history, tomboy is often related with lesbian even though it is not absolutely intended to the orientation sexual indicator. According to Avon Longitudinal Study of Parents and Children, a female who has behavior like a male is influenced by a genetic factor. Tomboy is also interested in science and technology as well (4)

Masculin comes from France Masculine, it is an adjective, it means a male or something pointed male characteristics. The opposite one is a female. Masculine is muscular, tough, strong, macho and logical, however masculine is identical with a man who wears a suit in order to be more good looking and touch (4). The masculine is adapted by a female to construct herself to be more touch and strongly.

Related with the phenomenon of the Social construction of masculine women identity refers to the theory of social reality construction through the action and interaction where the individual creates a reality continuously and having all together objectively (5). The process of the purpose done by every single person towards the environment consists of the process of externalization, internalization, and objectivities. Externalization is the adaptation of socio-cultural sector as the human product; objectivities is social interaction in intersubjective sector or having the process of institutionalization. Internalization is the individual identification in a social division where every single person becomes a member as well (6).

The reason why the researcher takes the subject of masculine women in Garut University because the researcher is eager to uncover something inside and undiscovered of them so the researcher could find out something interesting and unique. A crew cut of women identity construction in Garut University could be seen from Externalization, Objectivities and Internalization, in this case, the researcher does the research to help and find out the explanation the Externalization, Objectivities and Internalization's Model. The purpose of this research to discover and reveal the social construction of masculine women identity in terms of externalization, objectivation, and internalization.

\section{Methodology}

This research applies the theory of social reality construction which explains as the process of social through the action where every single person creates a reality continuously and having al together objectively (7). In this research, the researcher applies the technique of purposive sampling, it means that the determination of analysis unit considers certain criteria made towards deserved objects for the purposes of the research (3). This strategy is willing the informant chosen and based on the determination of the research with certain purposes. This research takes 5 informants as the data, 1). a female with short hair with the length of the hair approximately $3-5 \mathrm{~cm} ; 2$ ). Tomboy; 3). masculine appearances like a male; 4). happier and comfortable to gather with men, the criteria of informants are female masculine at Garut University at the third and seven semesters, they are consist of 2 students from Math and Science Faculty, 2 students from Communication Faculty and 1 student from Economic Faculty.

\section{Results and Findings}

\subsection{Social Construction of Masculine Women Identity Previewed from Externalization Side}

Externalization is the process in which the individual endeavors to adapt to the society and in that adaptation moment, the medium which she uses is a language or even an action. Human uses the language to adapt to his or her socio-cultural world and then his or her action is adapted to his or her socio-cultural world. Sometimes the people who can adapt to the society can see this moment and sometime they also cannot adapt to it. The acceptance and refusal depend on whether or not the individual can adapt to their sociocultural world (8)

Related to masculine women previewed from externalization side, fundamentally, masculine women have the potential to interact with the family, their friends at the campus or even outside the campus (society). When those masculine women can communicate, interact with their style and masculine appearance, these can adapt to the socio-cultural world. Based on the result of this research related to the social identity of women previewed from externalization side, namely each informant who has been interviewed gets affected from internal and external where we can see their appearance.

The internal factor can be affected by the family who makes the informant show their social construction identity of masculine women to the society. Along with the time, the informants can adapt to the environment well either in the society or in a campus environment. Some statements are taken from interviews (with $\mathrm{KH} /$ Cuneng), namely Since she was born, she was treated as a boy by her parents, especially by her father. She was given the clothing, toys and even treated as if she were a boy because her father had two sons so that KH/Cuneng was accustomed to whatever the boy would be. In line with $\mathrm{KH} / \mathrm{Cuneng}$, Am, the informant, states that the family becomes the main factor which makes her look masculine, as AM expresses that "yes, it was said by my father that he was willing to have a son during her wife's pregnancy, but on the contrary her wife bore a daughter so I become masculine." Whereas WD says that since she was the child she was often given toys (always played by boys) by her father so that her she behaves like a man and is accustomed to being masculine. Family factor gives the big affects to the child's growth because although the women are masculine she can adapt to the environment around either in family or society. However, the external factor related to masculine women identity is affected by the association with boyfriends and technological advance (mass media) as well as has the contribution in forming the character towards the social construction of masculine women so that it can affect the style and the hair style that is felt comfortable. In this essence of the matter, the externalization of masculine women is categorized as social process through the action in which the individual continually creates the realities which she owns and feels together and they are subjectively looked that the masculine women can construct herself to have the positive view and arrange the social forms which give the meaning to all fields of her life. The language used by the informant when adapting to the socio-cultural world is using the words or different language between women and men while adapting. Then their action is appropriate with whomever people to communicate with the masculine women. As adapting with another informant, sometimes it feels clumsy and uses the rude language. Besides that, her action is habit limited, because she cannot become herself. If she gathers around with the man, some informants feel free when communicating by using the daily language and her action does not block her or looks comfort around boyfriends. Figure 1 shown the communication model of the externalization of masculine women. 


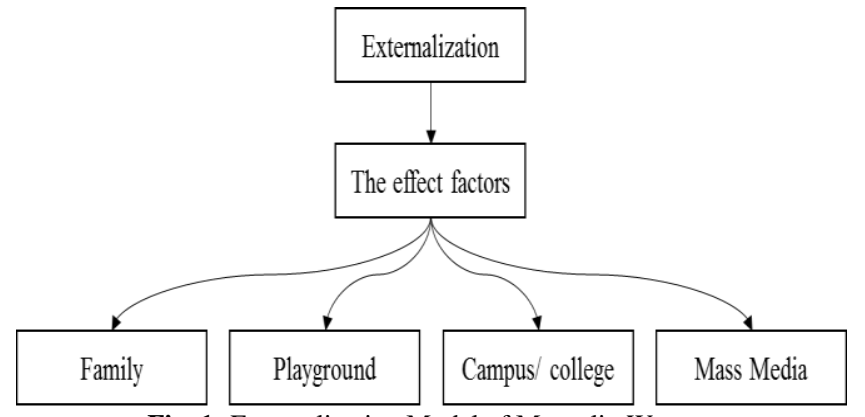

Fig. 1: Externalization Model of Masculin Women

\subsection{Social Construction of Masculine Women Identity Previewed from Objectivation Side}

Objectivation is where an individual will endeavor to interact with the socio-cultural world. In objectivation, that social reality is as if outside human. It becomes objective reality so that we feel there will be two realities, namely subjective-self and objective outside reality. These two realities form an inter-subjective network through an institution or institutional processes. Institute or institutional processes is a process to construct awareness into an action. In that institutional process, the values which become a guidance to interpret an action have become the parts which cannot be separated, so that what we are aware of is what we do (9).

Objectivation related to Masculin Women Identity is seen from either positive or negative response. As one of the informants uttered, whose name is FRB, she responds well and considers it as a common thing so that he does not have a problem with her family when looking masculine. The followings are his statements "the response from her family is common and not too surprising with her look because she is used to looking masculine since she was a child so her parents do not regard her as a problem with her look, but they hope her manner does not diverge." It is all the same as $\mathrm{KH} /$ Cuneng uttered when interviewed directly that "everything is common, not to act over and do not let her fall into the negative thing." However, the informant 'WD' states that the family responds commonly and he treats her as a boy by her father. Fundamentally, all informant's families set their daughters to look masculine in a proper way and not to fall them into harming themselves, so it can give them fit feeling and self-confident while associating.

Related to masculine appearance, there are some close friends who suggest and criticize the appearance and hair style, as follows: to criticize oneself to turn them into feminine, as such longing their hair to look better. It is different with FRB's opinion and he says that the direct response is made from around people when walking with their girlfriends who look feminine, many people pay attention and think negatively to them, FRB is aware of people's action around them who perhaps thinks that women like man are considered LGBT. It is the same as FNF utters on the next interview that a woman like a man (masculine) obtains the negative stereotype there are some people saying that whether FNF's boyfriend/ girlfriend is a woman too or a man.

Masculine women obtain positive and negative responses from other; positive response makes masculine women feel happy as the informant state, namely: FRB here states that she feels happy because there are some people thinking positively whereas there are some people putting her into a corner and responds her not well. However, FNF here states that she feels happy because there are some people appreciating her appearance and often suggesting her for her good hairstyle for herself.

Masculine women are also often responded negatively, this makes some of masculine women or informants ignore that negative response as $\mathrm{AM}$ who ignores people responding her not well or negatively to her on the next interview utters. As AM expressed that she ignores more to people's responses though it is best for her to be advised by people. But, that opinion makes feel her un- comfortable so she ignores whatever people will give opinion towards her.

Based on the result of this research, related to Social construction of masculine women identity previewed from objective side to social construction of masculine women is how masculine women themselves show their identity to other people and obtain the responses to people around about her, they consider her usual and normal because her close friends respond positively towards her appearance. This can be found that the informants try to interact with her sociocultural world, which has formed the intersubjective world through the institutional process, namely to be admitted by her friends or a group of people who often join with the informant in this research. Besides that, their responses to the masculine women form their social identity and they are more interested in their masculine appearance so that the critics towards her are often ignored and she does not really care of people's insult. The researcher creates a communications model of women's objectivation who looks masculine on Figure 2.

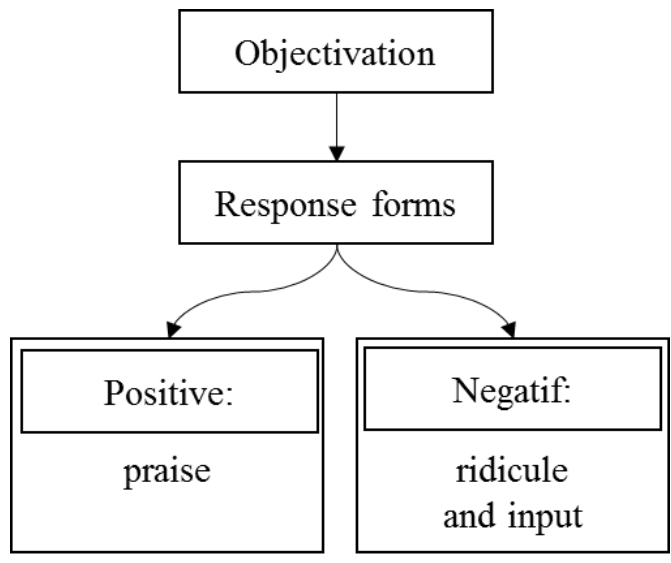

Fig. 2: Objectivation Model of Masculin Women

\subsection{Social Construction of Masculine Women Identity Previewed from Internalization Side}

Internalization is self-moment identification in a socio-cultural world. It is an individual process which conducts selfidentification in the socio-cultural world. The internalization is the withdrawal moment from social reality into oneself or social reality into subjective reality. Social reality is in humans themselves and with that method, human themselves will be identified in socio-culture (10). On the last interview about social construction identity of masculine women, it is previewed from internalization side that feeling comfortable towards the masculine women's appearance has become difficult for one self-identity to vanish, so that everything considers those becoming the part of themselves as some informants state that feeling very comfortable and becoming part of themselves and it is not someone's force in masculine appearance. The informant FNF states she feels very comfortable to have the short hair more than growing the long hair which is considered not simple. Feeling more comfortable, masculine women feel more self-confident with their appearance to other people as $\mathrm{KH} /$ Cuneng who has the short hair and looks masculine states.

All informants'self-confident feeling and comfort, especially in masculine women have the same statement. The comfort level and self-confident feeling which appear make masculine women feel satisfied with their appearance as some informants state when interviewing them, namely the informant FRB who states that this is her will at heart and she is willing to show her identity backed up by the positive response. It makes them feel self-confident and satisfied with their decision to look masculine. However, KH/ Cuneng says that she feels satisfied because she looks masculine for ages and it is not counterfeit to look 'cool'.

While FRB here says that the appearance will stay masculine, but will be masculine more, because we feel more comfortable and 
there will be no counterfeit or positive response even becomes only a praise which only effects to hair style and their appearance does not impact anything.

Based on the result of the research, the researcher obtains the result of how the Social construction of masculine women identity previewed from internalization side towards the social identity of masculine women, namely that self-acknowledgment from other people makes masculine women feel comfortable and selfconfident with their masculine look. That comfort will reform the construction in masculine women so that the informants do not have to alter themselves because they have considered themselves as something personal. This is caused by the responses from objective reality and then developed by themselves that that appearance does not violate the rule. This is also social reality withdrawal to masculine women or informants by expressing their feeling comfortable, self-confident and self-constructing to stay masculine in socializing with other people. The researcher creates the internalization communications model of Masculine women on Figure 3.

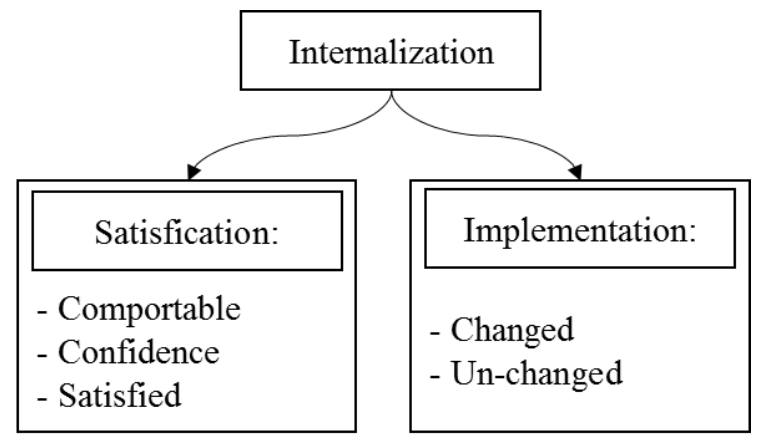

Fig. 3: Internalization Model of Masculin Women

\section{Conclusion}

Based on the result of the research, it has previously been brought forward and we can conclude that the research about "Social Construction of Masculine Women Identity" at Universitas Garut is: The social construction of masculine women identity previewed from various externalization obtains the good effect either inside or outside. That effect can form their self-identity, especially from family factor, friends, schools or even mass media. They do this as a result of character forming since they were children and it becomes the atmosphere in forming the character when they grow adult, as well as they are treated as if they were a man and applying mimic process since they were children.

The social construction of masculine women identity previewed from masculine women objectivation shows their self-identity toward others and they obtain the responses from people around them about themselves and they consider it as a normal and common. The closest people of those masculine women responds more positively to their looks although there will be mock and advice they obtain.

The social construction of masculine women identity previewed from internalization obtains the satisfaction of their appearance, such as feeling comfortable, self-confident of their looks. What they feel comfortable then raises their self-confidence and selfsatisfaction, so that masculine women are not willing to alter their appearance because they have become used to it.

\section{References}

[1] Manda D, Suardi. Masculine women. Equilib Educ J. 2016;2(1):57-66.

[2] Daryanto. Communication Studies. Bandung: PT. Tutorial Mode of Conscience Sejahtera; 2011.

[3] Sugiono. Quantitative Research Methods, Qualitative and R \& D. Bandung: Alfabeta; 2010
[4] Wikipedia. Wikipedia. 2016. p. Tomboy.

[5] 10 Berger ScConstrReal FoundKnowEvydyLife.pdf

[6] Bungin B. Sociology of Communication: Theory, Paradigm, and Discourse \& Communication Technology in Society. Jakarta: Kencana Prenada Media Group; 2006.

[7] Nurhadi ZF. Theory of Communication (Communication Theory Qualitative Research in Perspective). Bogor: Ghalia Indonesia; 2015.

[8] Halberstam J. Female Masculinity. Durham: Duke University Press; 1998.

[9] Rubent B, Lea P S. Communication and Human Behavior. Jakarta: PT. King Grafindo Persada.; 2013.

[10] Fakih M. Analysis of Gender and Social Transformation. Yogyakarta: PT Pustaka Student; 1996. 